\title{
Digitization, Customer Engagement and Performance of Small and Medium Enterprises in Ghana
}

\author{
${ }^{1}$ Daniel Quaye, ${ }^{2}$ Isaac Mensah, ${ }^{3}$ Charles Andoh \\ ${ }^{1,2}$ Department of Marketing and Entrepreneurship, University of Ghana Business School, Legon \\ ${ }^{3}$ Department of Finance, University of Ghana Business School, Legon
}

\begin{abstract}
The technology revolution and associated benefits have encouraged businesses in developed economies to invest and benefit from digital technologies. While benefits of digitization remain certain in some developed economies, the benefits of digitization to SMEs in Ghana remain uncertain. To understand and address the benefits or otherwise of digitization among SMEs in Ghana, the researchers theoretically ground their research model in resource capability base view, and empirically test the impact of digitization on performance illuminating the outcome. Two hundred and fifty three (253) small and medium sized entrepreneurs were randomly selected from Ghana for the study. Structural equation modelling was employed to test the proposed structural relationships. Customer engagement partially mediates the effect of general-use (access) and communication-integration (integration) digitization on performance of SMEs in Ghana but fully mediate market-oriented (leverage) digitization. The study found that SMEs in Ghana are yet to fully adopt, use and synergize their operations with digital technologies. The paper also found that using digital technologies to engage customers provide a significant performance effect. The paper concludes that access to digital technologies, integration of digital technologies and market-focus orientation of entrepreneurs are factors that would enhance the digitization of Ghanaian SMEs, leading to better performance. This study provides actionable recommendations for SMEs regarding the performance effects of digital application and extends the understanding of Resource-based view theory in relation to SME digitization.
\end{abstract}

Keywords: customer engagement; digitization; performance; SMEs; technologies 